\title{
Selection of Cell Lines with High Productivity of Shikonin Derivatives by Protoplast Culture of Lithospermum erythrorhizon Cells
}

\author{
Yasuhiro FuJIta, Shigeru TaKahashi and Yasuyuki Yamada* \\ Bioscience Research Center, Mitsui Petrochemical Industries, Ltd., \\ Waki-machi, Kuga-gun, Yamaguchi 740, Japan \\ *Research Center for Cell and Tissue Culture, Kyoto University, \\ Kyoto 606, Japan \\ Received November 8, 1984
}

\begin{abstract}
We selected high-yield cell lines, using protoplast culture of Lithospermum erythrorhizon cells. Three cell lines having different shikonin productivities were used as parent cells for the selection, and cell lines with high productivity were obtained efficiently in every case. The best cell line had $6.45 \mathrm{~g}$ shikonin/g inoculum/23 days of production which was almost 1.5 times higher than that of the original cell line. The productivities of protoplast-derived cell lines were distributed widely and their average productivity was similar to the original one. The subculture of such a protoplastderived cell line for eight months showed that its shikonin productivity was stabler than the original cell line.
\end{abstract}

Shikonin derivatives from the root of a medicinal plant, Lithospermum erythrorhizon have long been used, in Japan, as dyestuffs and as a medicine for wounds, burns, etc.

Tabata et al. had first found that callus tissue of L. erythrorhizon produced shikonin derivatives on Linsmaier-Skoog agar medium. ${ }^{1)}$ The production from cell suspension cultures became possible by our studies on media and on the production system. ${ }^{2 \sim 5)}$ The commercial production of such metabolites has already been achieved. ${ }^{6)}$

The selection of high-yield cell lines is also important to improve the production of shikonin derivatives. A typical method is to separate a cell aggregate having high productivity from the parent cultured cells. The selection efficiency of this method is relatively low and the productivity of selected cell lines is frequently unstable. ${ }^{7)}$ Cell lines of L. erythrorhizon selected by this method in our research had relatively unstable productivity of shikonin derivatives, and we had to continue such selection to keep up the commercial production. One possibility for such instability could be the presence of many chemotypes within an orig- inal cell aggregate. ${ }^{8)}$ To solve such problems, it is thought that original cells should be separated into single cells and the selection would be performed among single cell clones. ${ }^{9)}$ To obtain single cells, several methods are already known, such as the separation of free cells by filtration, the maceration of cell aggregates with enzymes, and the isolation of protoplasts. We have chosen to isolate protoplasts, since protoplasts are absolutely single cells and the other methods frequently offer a mixture of single cells and small clumps.

We have reported the isolation and the culture of L. erythrorhizon protoplasts. ${ }^{10)} \mathrm{We}$ here describe the shikonin productivity of protoplast-derived cell lines and the selection of high-yield cell lines from them.

\section{MATERIALS AND METHODS}

Cell culture. Three cell lines having different shikonin productivities, MM-1, MM-2, and MM-3 were used. MM2 and MM-3 were obtained originally from MM-1 by repeating the cell aggregate selection several times. These lines of $L$. erythrorhizon were subcultured as described previously, ${ }^{2)}$ and cells cultured for 7 to 9 days were used for the isolation of protoplasts. 
Protoplast culture. The isolation and the culture of protoplasts have been described previously. ${ }^{10)}$ After about 2 months culture of the protoplasts, cell colonies grown to 0.5 to $1.0 \mathrm{~mm}$ in diameter were transferred to LinsmaierSkoog agar medium containing $0.266 \mathrm{M}$ glucose as osmoticum and supplemented with $10^{-4} \mathrm{M} 3$-indoleacetic acid and $10^{-6} \mathrm{M}$ kinetin. Cell colonies grown for 4 weeks on the medium were then transferred to the same agar medium without the osmoticum and cultured for 3 weeks. Protoplast-derived callus obtained in this manner was inoculated into the liquid medium of the original cell line, and the productivity of protoplast-derived cell lines was examined after the third subculture generation.

Examinations of shikonin productivity. Protoplastderived cells ( $0.5 \mathrm{~g}$ in $27 \mathrm{ml}$ of the subculture medium) were cultured for 9 days. The grown cells $(0.8 \mathrm{~g})$ were then cultured for 14 days in M-9 medium of which components have been reported previously. ${ }^{3)}$ The shikonin derivatives were extracted from dried cells with ethanol and their amounts were determined by the methods of Mizukami et al. ${ }^{11)}$ The growth rates in the former 9 days and in the

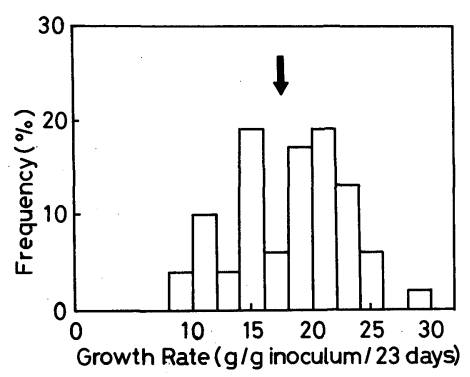

FIG. 1. Distribution of Growth Rate of Protoplastderived Cell Lines.

The number of examined cell lines was 48 . The growth rate was determined based on the dry weight. An arrow shows the growth rate of the original cell line MM-2.

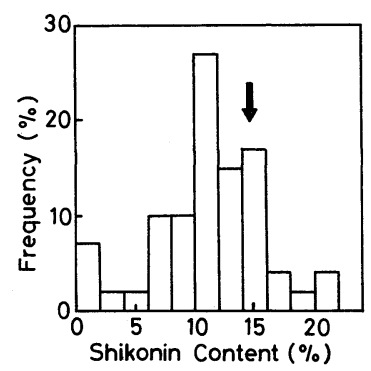

FIG. 2. Distribution of Shikonin Content of Protoplastderived Cell Lines.

The number of examined cell lines was 48 . The shikonin content was determined based on the dry weight of obtained cells. An arrow shows the shikonin content of the original cell line MM-2. latter 14 days were independently determined based on the dry weight of cells, and the growth rate in 23 days was calculated from them.

\section{RESULTS}

\section{Shikonin productivity of protoplast-derived cell lines}

Many cell lines were obtained from the protoplast culture of the original cells, MM-2, which had $17.5 \mathrm{~g} / \mathrm{g}$ inoculum $/ 23$ days of the growth rate, $14.6 \%$ of the shikonin content and $2.56 \mathrm{~g}$ shikonin/g inoculum/23 days of the productivity. We chose 48 cell lines among them at random, and studied the shikonin production of protoplast-derived cell lines. As a result, their growth rates, contents and productivities were distributed widely in the range from 8.2 to $28.5 \mathrm{~g} / \mathrm{g}$ inoculum $/ 23$ days, from zero to $21.2 \%$, and from zero to $4.66 \mathrm{~g}$ shikonin/g inoculum $/ 23$ days respectively

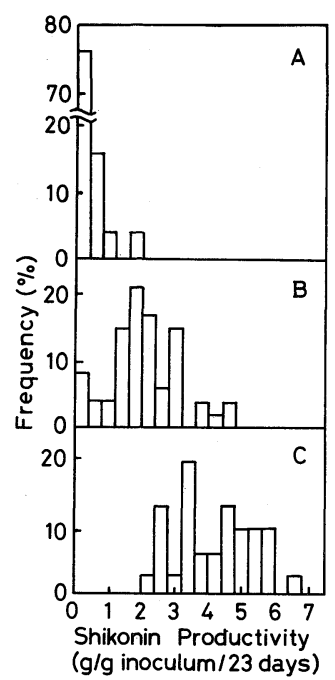

FIG. 3. Distribution of Shikonin Productivity of Protoplast-derived Cell Lines.

The shikonin productivity showed the total amount of shikonin derivatives obtained from $1.0 \mathrm{~g}$ dry weight of inoculum after 23 days culture. A: The original cell line was MM-1 having $0.2 \mathrm{~g}$ shikonin/g inoculum/23 days of productivity, and the number of examined cell lines was 25 . B: The original cell line was MM-2 having $2.56 \mathrm{~g}$ shikonin/g inoculum/23 days of the productivity, and 48 cell lines were examined. C: The original cell line was MM-3 having $4.2 \mathrm{~g}$ shikonin $/ \mathrm{g}$ inoculum $/ 23$ days of the productivity, and 30 cell lines were examined. 
Table I. Average Productivity of Protoplast-Derived Cell Lines

\begin{tabular}{lccc}
\hline & $\begin{array}{c}\text { Growth rate } \\
(\mathrm{g} / \mathrm{g} \text { inoculum })\end{array}$ & $\begin{array}{c}\text { Content } \\
(\%)\end{array}$ & $\begin{array}{c}\text { Productivity } \\
(\mathrm{g} / \mathrm{g} \text { inoculum })\end{array}$ \\
\hline MM-1 & & & \\
Original & 1.7 & 12 & 0.2 \\
Average & 1.8 & 13 & 0.2 \\
\hline MM-2 & & & \\
Original & 17.5 & 15 & 2.6 \\
Average & 18.4 & 11 & 2.0 \\
\hline MM-3 & & & \\
Original & 23.9 & 18 & 4.2 \\
Average & 25.1 & 17 & 4.2 \\
\hline
\end{tabular}

Culture period, 23 days.

(Figs. 1 3). The productivity of 15 cell lines out of 48 exceeded the original MM-2 and the best cell line showed almost double the productivity of MM-2. The average values of the 48 lines, $18.4 \mathrm{~g} / \mathrm{g}$ inoculum $/ 23$ days of the growth rate, $11.0 \%$ of the content, and $2.0 \mathrm{~g}$ shikonin/g inoculum/23 days of the productivity, were similar to the corresponding value of the original line (Table I).

\section{Selection from cell line $M M-1$}

We studied such selection from the original cell line, MM-1, which had a low shikonin productivity. The growth rate, the content, and the productivity of MM-1 were $12.0 \mathrm{~g} / \mathrm{g}$ inoculum $/ 23$ days, $1.7 \%$, and $0.2 \mathrm{~g}$ shikonin $/ \mathrm{g}$ inoculum/23 days, respectively. We chose 25 cell lines from protoplast-derived cell lines and examined them. The distribution of their productivities was also wide, in the range from zero to $1.80 \mathrm{~g}$ shikonin $/ \mathrm{g}$ inoculum $/ 23$ days and the productivity of the best one was about 9 times higher than the original MM-1, although about half of the 25 lines were nonproducing or slightly producing (Fig. 3). Their average productivity was also similar to the corresponding value of MM-1 (Table I).

\section{Selection from cell line $M M-3$}

The original cell line was MM-3, which had a high productivity; $23.9 \mathrm{~g} / \mathrm{g}$ inoculum/23 days

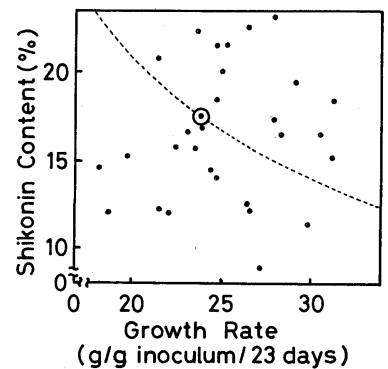

FIG. 4. Relation between Shikonin Content and Growth Rate of Protoplast-derived Cell Lines.

The original cell line was MM-3. Dotted line shows the same productivity as MM-3. 0 , protoplast-derived cell lines; $\odot$, MM-3.

Table II. Shikonin Productivity of Selected Cell Lines

\begin{tabular}{cccc}
\hline $\begin{array}{c}\text { Selected } \\
\text { cell line }\end{array}$ & $\begin{array}{c}\text { Growth rate } \\
(\mathrm{g} / \mathrm{g} \text { inoculum })\end{array}$ & $\begin{array}{c}\text { Content } \\
(\%)\end{array}$ & $\begin{array}{c}\text { Productivity } \\
(\mathrm{g} / \mathrm{g} \text { inoculum })\end{array}$ \\
\hline $\begin{array}{l}\text { Original } \\
\text { cell line } \\
-----\end{array}$ & 23.9 & 17.6 & 4.20 \\
A & 27.8 & 23.2 & 6.45 \\
B & 26.4 & 22.6 & 5.97 \\
C & 31.2 & 18.5 & 5.78 \\
D & 29.1 & 19.5 & 5.68 \\
E & 24.6 & 21.6 & 5.32 \\
\hline
\end{tabular}

Culture period, 23 days.

of the growth rate, $17.6 \%$ of the shikonin content, and $4.2 \mathrm{~g}$ shikonin $/ \mathrm{g}$ inoculum $/ 23$ days of the productivity. Examinations of 30 protoplast-derived lines showed that their productivities were also distributed in a wide range (Fig. 3), and the average value was almost the same as the original MM-3 (Table I). In this case, there was no contamination of non-producing cell lines in the 30 lines examined, and the productivity of 14 lines out of the 30 exceeded the original MM-3. As shown in Table II, we could select high-yield cell lines from this study. The best line had $6.45 \mathrm{~g}$ shikonin/g inoculum/23 days of the productivity which was around 1.5 times higher than the original MM-3.

We studied the relationship between the growth rate and the shikonin content of protoplast-derived lines. As shown in Fig. 4, 


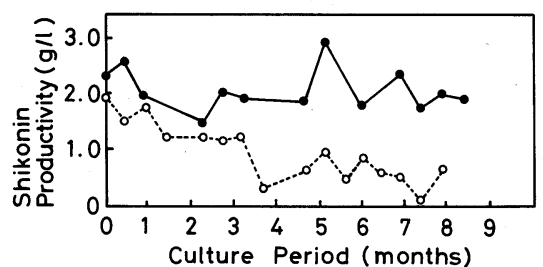

FIG. 5. Stability of Shikonin Productivity of Protoplastderived Cell Line.

The shikonin productivity showed the total amount of shikonin derivatives contained in one liter of M-9 medium after 14 days culture. $\bigcirc$, protoplast-derived cell line; $\bigcirc$, original cell line (MM-3).

points indicating protoplast-derived lines were distributed equally and widely surrounding the point of MM-3, and it was found that distributions of the growth rate and the shikonin content were independent of each other. This phenomenon was commonly observed in all selection cases described here.

\section{Stability of shikonin productivity}

Protoplast-derived cell lines and the original MM-3 have been subcultured in every 2 weeks for 8 months. The productivity of the parent line MM-3 started to decrease after 4 months of culture and the remaining productivity after 8 months was only one-third of the initial value. On the contrary, the protoplast-derived cell lines have maintained a constant productivity for 8 months, although some fluctuations were observed (Fig. 5).

\section{DISCUSSION}

The three parent lines used here had been obtained by repeating the common selection method using the separation of each cell aggregate in the original cultured cells. For the acquirement of the cell line MM-3 which had superior productivity, it took much effort and time.

Single cell selection should be efficient, but no success of such work has been reported except for a few examples using a mixture of single cells and small clumps. ${ }^{9)}$

We tried, therefore, such selection using protoplasts as single cells. As shown in Fig. 3, a superior cell line having 9 times higher productivity than the original MM-1 could be obtained in only one selection process which took merely 4 to 6 months. Even when the high-producing MM-3 line was used as parent cells, the cell line having 1.5 times superior productivity could be selected. These facts show that protoplast selection is efficient.

We observed the following points as common phenomena in all selection cases discussed here.

(1) There is no relationship between the growth rate and the shikonin content of protoplast-derived cell lines.

(2) Their growth rates, shikonin contents, and productivities are distributed widely around the corresponding value of the original cell line.

(3) Each average value of their growth rates, shikonin contents, and productivities is similarly to the corresponding value of the original cell line.

These facts indicate that cell lines derived from many chemotypes within the original cell aggregate could be picked up equally and widely by this protoplast method, so such a distribution would show the composition of chemotypes in the original cell aggregate.

High-producing and stable cell lines should be obtained by selection. As discussed here, it was proved that the protoplast method was very effective in obtaining high-yield cell lines for shikonin derivatives, and the productivity of the protoplast-derived cell line was much stabler than the original cell line. The improved stability would be due to the uniformity of the properties of protoplastderived cells. To clarify this point, we are trying to repeat the protoplast selection and to analyze the distribution of the shikonin productivity.

\section{REFERENCES}

1) M. Tabata, H. Mizukami and N. Hiraoka, Phytochemistry, 13, 927 (1974).

2) Y. Fujita, Y. Hara, T. Ogino and C. Suga, Plant Cell Reports, 1, 59 (1981).

3) Y. Fujita, Y. Hara, C. Suga and T. Morimoto, Plant 
Cell Reports, 1, 61 (1981).

4) Y. Fujita, M. Tabata, A. Nishi and Y. Yamada, Proceedings, 5th Intl. Cong. Plant Tissue \& Cell Culture, Tokyo, Japan, 1982, p. 399.

5) Y. Yamada and Y. Fujita, "Handbook of Plant Cell Culture," Vol. 1, ed. by D. A. Evans, W. R. Sharp, P. V. Ammirato and Y. Yamada, Macmillan Publishing Co., New York, 1983, p. 717.

6) M. E. Curtin, Biotechnology, 1, 649 (1983).

7) M. H. Zenk, "Frontiers of Plant Tissue Culture
1978," ed. by T. A. Thorpe, IAPTC, Calgary, 1978, p. 1.

8) F. Constabel, Plant Cell Reports, 1, 3 (1981).

9) T. Ogino and M. Tabata, Phytochemistry, 17, 1907 (1978).

10) Y. Maeda, Y. Fujita and Y. Yamada, Plant Cell Reports, 2, 179 (1983).

11) H. Mizukami, M. Konoshima and M. Tabata, Phytochemistry, 16, 1183 (1977). 